\title{
Experimental and Numerical Investigation of Temperature Development of Ohmic Heating Cured Nonmass Concrete under Subzero Temperature
}

\author{
Beimeng Qi, ${ }^{1}$ Zheng Zhou, ${ }^{2}$ Weichen Tian $\left(D^{2}{ }^{2}\right.$ Mingzhe Ouyang, ${ }^{2}$ Xiaocheng Wang, ${ }^{3}$ \\ Qiang Shi, ${ }^{3}$ Ye Wang, ${ }^{3}$ Yang Sun, ${ }^{4}$ and Wei Wang ${ }^{2}$ \\ ${ }^{1}$ College of Quality \& Safety Engineering, China Jiliang University, Hangzhou 310018, China \\ ${ }^{2}$ School of Civil Engineering, Harbin Institute of Technology, Harbin 150090, China \\ ${ }^{3}$ State Grid Inner Mongolia East Power Co., Ltd., Construction Branch, Hohhot 010000, China \\ ${ }^{4}$ State Grid Inner Mongolia East Power Co., Ltd., Institute of Economics and Technology, Hohhot 010000, China
}

Correspondence should be addressed to Weichen Tian; tianweichen@hit.edu.cn

Received 3 April 2021; Revised 24 May 2021; Accepted 25 May 2021; Published 15 December 2021

Academic Editor: Xianming Shi

Copyright (C) 2021 Beimeng Qi et al. This is an open access article distributed under the Creative Commons Attribution License, which permits unrestricted use, distribution, and reproduction in any medium, provided the original work is properly cited.

In this paper, carbon fiber/carbon nanofiber strengthening nonmass concrete slab was designed, and ohmic heating $(\mathrm{OH})$ curing was used to promote the strength formation of the slab under $-20^{\circ} \mathrm{C}$. COMSOL multiphysical field coupling program has been used to simulate the heating process of nonmass concrete slabs under different conditions. COMSOL analysis results showed that the optimal loading power density of $\mathrm{OH}$ cured sample under $-20^{\circ} \mathrm{C}$ was $1000 \mathrm{~W} / \mathrm{m}^{2} \sim 1200 \mathrm{~W} / \mathrm{m}^{2}$. Moreover, numerical analysis results were experimentally validated by the multipoint temperature measurement method. Furthermore, the mechanical properties showed that the compressive strength of the sample cured by 2 days $\mathrm{OH}$ curing at $-20^{\circ} \mathrm{C}$ reached up to $48.2 \mathrm{MPa}$. SEM analysis exhibited that $\mathrm{OH}$ curing could improve the interfacial transition zone (ITZ) between the fiber and the matrix, leading to a denser microstructure. This study proved that COMSOL program could provide good theoretical guidance for $\mathrm{OH}$ cured nonmass cement concrete under subzero temperature. This work establishes an accurate guideline for electric power supplementation, laying a solid foundation of winter construction with high efficiency and low energy consumption.

\section{Introduction}

Concrete is a common material, which has attracted wide attention in the construction industry due to its low cost and excellent mechanical properties. However, cementitious materials fail to hydrate under subzero temperature conditions. Therefore, the preparation of concrete structures under subzero temperature is still a serious problem. As a result, the concrete construction in cold region in winter is greatly restricted, which affects the economic development. Traditional curing methods for winter concrete construction mainly include thermal insulation curing and external heating curing method $[1,2]$. These methods have been utilized to protect concrete structure from being frozen. However, these methods only can be utilized under moderate conditions and will bring some unpreventable problems. To be specific, external heating curing method works by heating the air around the structure or directly heating the concrete. It is hard to operate and requires much energy consumption. Thermal insulation curing is conducted by covering heating preservation material on the concrete to slow down the heat release. This method is easy and inexpensive to achieve, while it is not suitable for the cold environment with the temperature lower than $-10^{\circ} \mathrm{C}[3]$. Thus, there is an urgent need for developing a new curing method for curing cementitious materials under ultra-low temperature that is energy-saving and environmentally friendly to meet the structural strength requirements $[4,5]$. 
Ohmic heating $(\mathrm{OH})$ curing method utilizes the ohmic heating generated by the action of electric current to cure cementitious materials. At present, a series of research results proved that $\mathrm{OH}$ curing could improve the strength formation of cement-based materials. Kovtun [6, 7] utilized direct current for $\mathrm{OH}$ curing of alkali activated cementitious materials containing fly ash under positive temperature. Temperature development was found to be closely related to the formation of strength with different voltage gradient conditions. However, with the progress of hydration, the electric conductivity of the cementitious materials degraded without the addition of conductive fillers, resulting in the decrease of the curing temperature [8]. Under this circumstance, Liu [9] cured cementitious materials incorporated with carbon nanofibers (CNFs) as conductive fillers with $12 \mathrm{~h} \mathrm{OH}$ curing at $-20^{\circ} \mathrm{C}$ and successfully raised the compressive strength of the sample to $27.7 \mathrm{MPa}$ above the critical frost resistance strength of $3.5 \mathrm{MPa}$. Furthermore, Liu [10] conducted $\mathrm{OH}$ curing on the CF/CNFs reinforced cementitious composites under ultra-low temperature. The compressive strength of the sample reached up to $49.2 \mathrm{MPa}$ with 2 days $\mathrm{OH}$ curing under $-20^{\circ} \mathrm{C}$. Above all, the previous work has solidly shown that $\mathrm{OH}$ curing method can be used as a novel and effective curing method for concrete construction under subzero temperature.

However, main researches on $\mathrm{OH}$ curing of cementitious materials under subzero temperature focused on the mechanical properties and hydration degree of small size concrete samples (such as $40 \mathrm{~mm} \times 40 \mathrm{~mm} \times 160 \mathrm{~mm}$ ); the researches on $\mathrm{OH}$ cured nonmass concrete structures are still blank. However, the study regarding the properties of nonmass concrete slab has been investigated a lot due to its significance [11]. To be specific, based on the maturity theory of strength development on cement-based materials, the temperature development inside the sample under subzero temperature is crucial to ensure the sufficient strength formation of the sample $[12,13]$. According to heat transfer theory, the heating process of small size structure can be regarded as a uniform heating process because of its low internal temperature gradient. However, for the cementitious materials with larger size and different geometries (such as nonmass concrete slab), the internal temperature gradient of the sample cannot be ignored, and the structure is more likely to suffer damage during $\mathrm{OH}$ curing process because of the large thermal expansion coefficient differences among the complicated components inside the sample [14-16]. Therefore, it is of vital significance to clarify the regularity of temperature development and corresponding influencing factors of $\mathrm{OH}$ cured nonmass concrete structures under subzero temperature. Also, it is essential to establish a numerical model to predict the temperature development of the structure.

COMSOL multiphysical field coupling program based on the solution of partial differential equations has been utilized widely to analyze realistic physical phenomena. For $\mathrm{OH}$ curing process, the modeling process is mainly based on Maxwell's equations and fundamental principles of heat transfer. $\mathrm{OH}$ curing process is considered to be the application of electrothermal on concrete structure, and
COMSOL program has been widely utilized in the field of electrothermal applications and concrete structure. To be specific, Zandi et al. [17] utilized COMSOL program to simulate the photogeneration, electrical properties, and heat distribution of graphene oxide contacting perovskite solar cells and effectively established the three-dimensional model of photo-electric-thermal and determined the promoting effect of graphene on the heating efficiency. Moreover, $\mathrm{Li}$ et al. [18] utilized COMSOL program to simulate the heating temperature development of external geothermal bridge system and the results were compared with the field test results. It was found that the simulated results were verified to accurately reflect the bridge heating efficiency in actual winter environment. Larwa et al. [19] simulated the heat flux and temperature distribution of phase change materials enhanced radiant floor systems by $2 \mathrm{D}$ model constructed by COMSOL program; it was verified that the utilization of COMSOL program could effectively reflect the heating situation of the system. In summary, COMSOL program can be expected to establish the relationship between different physical fields, especially in the electrothermal physical field. Therefore, COMSOL program has been utilized in this work to establish the model of heat distribution and temperature development within concrete structures cured by $\mathrm{OH}$ curing, so as to guide the $\mathrm{OH}$ curing process of concrete structures and promise the reasonable temperature distribution under subzero temperature.

In this paper, carbon fibers (CFs) have been utilized as macroscopic conductive fillers and CNFs were utilized as microscopic conductive fillers to synergistically prepare nonmass CFs/CNFs reinforced concrete slab (CFs/CNFs$\mathrm{CS})$ with the size of $350 \mathrm{~mm} \times 450 \mathrm{~mm} \times 40 \mathrm{~mm}$. COMSOL multiphysical field coupling program was utilized to establish the numerical prediction model of the temperature development and distribution of $\mathrm{OH}$ cured slab under subzero temperature. The effects of different influencing factors including loading power densities, environmental temperature, and structure geometric shape on the temperature development and distribution were discussed in detail. Moreover, the temperature development and distribution of the $\mathrm{OH}$ cured slab at $-20^{\circ} \mathrm{C}$ were experimentally measured to verify the accuracy of the numerical model. In addition, the mechanical properties of the $\mathrm{OH}$ curing nonmass CFs/CNFs-CS samples with optimized loading electric power were measured and SEM analysis was conducted to observe the microstructure of the samples.

\section{COMSOL Multiphysical Field Coupling Numerical Simulation}

The mutual coupling calculation among different physical fields (such as electric field and heat transfer field) can be realized by the COMSOL multiphysical field coupling program. In this work, $\mathrm{OH}$ curing process of nonmass concrete structure is closely related to the curing temperature and the environmental temperature, and the heat generation process is considered to be a transient process. Under this circumstance, COMSOL program was conducted to simulate the $\mathrm{OH}$ curing process of $\mathrm{CFs} / \mathrm{CNFs}-\mathrm{CS}$ under 
subzero temperature. The detailed modeling process is shown as follows:

(1) Definition of material parameters: the parameters of concrete structure provided by COMSOL database have been utilized to define some relevant parameters.

(2) Establishment of physical field: the $\mathrm{OH}$ curing process is a Joule heating process, thus the Joule heating module in COMSOL has been selected, which includes current module and transfer module of solid heating. The current module has also been used to calculate the electric field distribution, current distribution, and potential distribution in the samples cured by $\mathrm{OH}$ curing. Based on Ohm's law, the current conservation equation which utilizes scalar potential as the dependent variable has been solved. Its formula $[20,21]$ is shown as follows:

$$
\begin{aligned}
\nabla \cdot J & =Q_{j, y}, \\
J & =\sigma E+\frac{\partial D}{\partial t}+J_{e}, \\
E & =-\nabla V,
\end{aligned}
$$

where $J$ is the current density vector $\left(\mathrm{A} / \mathrm{m}^{2}\right) ; Q_{j, v}$ represents the general current source $\left(\mathrm{A} / \mathrm{m}^{3}\right) ; E$ represents the intensity of the electric field (N/C); $\sigma$ represents the conductivity (S/M); $V$ is the electric potential; and $D$ represents the relative dielectric constant (C2).

The features provided by the solid heating transfer module interface have been utilized to simulate the process of conduction convection and radiation heat transfer through heat flux and the surface settings of environmental radiation, in which, heat flux is defined as convection heat flux, and its expression $[22,23]$ is shown as follows:

$$
Q_{D}=h\left(T_{e x t}-T\right),
$$

where $Q_{D}$ is the convective heat transfer; $T_{\text {ext }}$ represents the external temperature; and $T$ is the temperature of the sample cured by $\mathrm{OH}$ curing. In this simulation, $h$ represents the coefficient of heat transfer.

The transfer of radiant heat is defined by the surface to environment radiation module, and its hypothesis equation $[24,25]$ is as follows:

$$
Q_{F}=\varepsilon \sigma_{1} A\left(T_{\text {ext }}-T\right),
$$

where $\varepsilon$ is the surface emissivity of the sample, which is also known as the blackness of the sample, the blackness of concrete value is $0.94 ; \sigma_{1}$ represents the Boltzmann constant with the value of $5.67 \times 10^{-8} \mathrm{~W} /$ $\left(\mathrm{m}^{2} \cdot \mathrm{K}^{2}\right)$; and $A$ is the surface area of the sample.
Electromagnetic-thermal module has been selected to conduct modeling analysis during the COMSOL process of multiphysical field coupling; electromagnetic-thermal module is selected to conduct modeling analysis on the multiphysical field coupling of samples under $\mathrm{OH}$ curing condition. Its transient response hypothesis equation [26] is shown as follows:

$$
\rho C_{p} \frac{\partial T}{\partial t}+\rho C_{p} u \cdot \nabla T=\nabla \cdot(k \nabla T)+Q_{e},
$$

where $\rho$ is the density of the sample; $C_{\mathrm{p}}$ is the constant pressure heat capacity of the sample (J/ $(\mathrm{kg} * \mathrm{~K})) ; u$ is the vector field constructed; and $K$ is the thermal conductivity $(\mathrm{W} /(\mathrm{m} * \mathrm{k}))$.

(3) Division of mesh grid: conventional grid division has been adopted. The size of the cuboid model is $350 \mathrm{~mm} \times 450 \mathrm{~mm} \times 40 \mathrm{~mm}$, and the size of the cylinder model is $200 \mathrm{~mm} \times 1200 \mathrm{~mm}$. The complete grid of the model consists of " 1465 " domain cells, 600 boundary elements, and 80 edge cells with the condition of conventional grid division. The results of cuboid model mesh division are shown in Figure 1(a), and the results of cylinder model mesh division are shown in Figure 2(a).

(4) Boundary conditions: the interface potential of one side has been set to be 0 in the current boundary conditions, and the electric potential of the opposite section is set to be Vtot, which is converted according to the power required by the experiment. The rest of the interfaces are set to be electrical insulation. The potential distribution diagram of the cuboid model is shown in Figure 1(b), and the potential distribution diagram of the cylinder model is shown in Figure 2(b). As shown below, the red area is considered as of high potential and the blue area is considered to be of low potential.

Solid heat transfer boundary conditions:

(1) It is assumed that the relevant material parameters (specific heat capacity, the coefficient of conductivity, and the conductivity) of the sample cured by $\mathrm{OH}$ curing remain unchanged during the process of heat transfer.

(2) Due to the low environmental temperature, no insulation layer is set, and all of the sections in the geometric model are considered to participate in the process of heat exchange.

(5) Output of calculation results: the temperature development of the samples cured by $\mathrm{OH}$ curing is considered to be a transient process, the temperature of the sample changes consistently with time, thus the research is determined to be transient. In this work, the length of calculation step was set to be $0.5 \mathrm{~min}$, and the calculation time was set to be $600 \mathrm{~min}$. The temperature probe was set at the center point of the model to record the temperature development during $\mathrm{OH}$ curing process. 


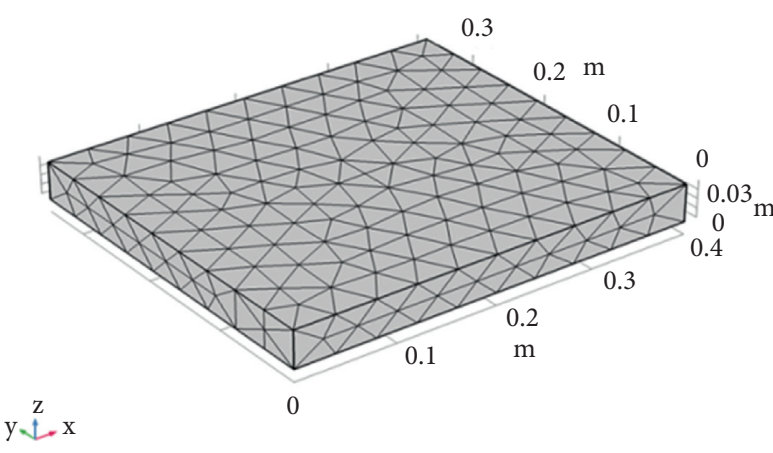

(a)

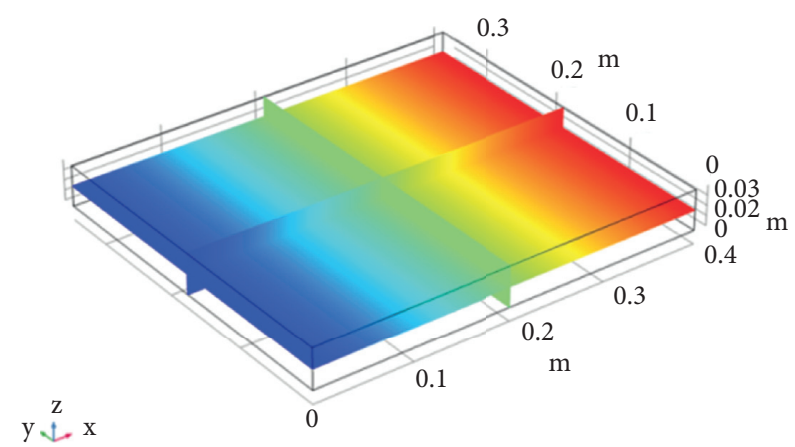

(b)

Figure 1: The generation of cuboid model: (a) grid division of cuboid model and (b) electrical potential distribution of cuboid model.

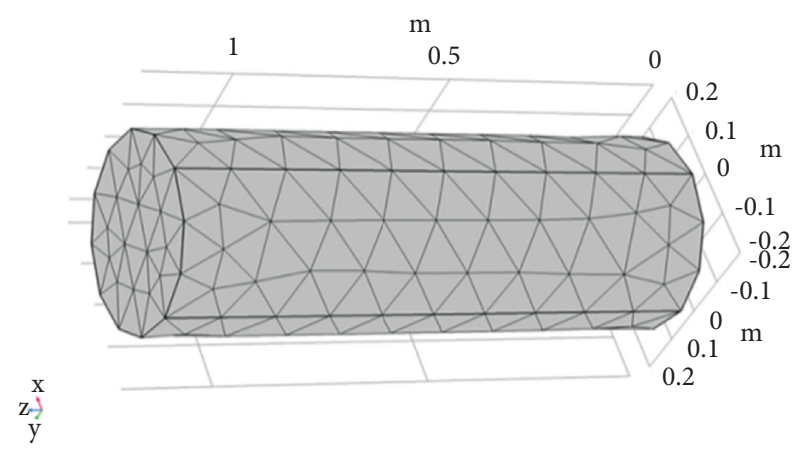

(a)

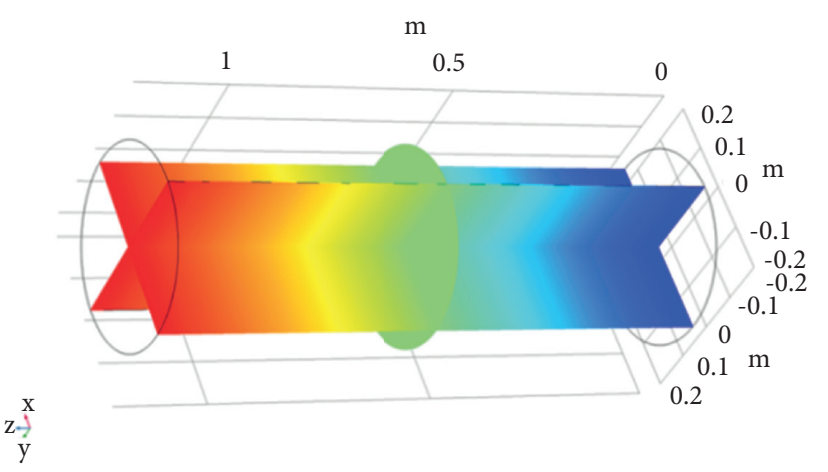

(b)

Figure 2: The generation of cylinder model: (a) grid division of cylinder model and (b) electrical potential distribution of cylinder model.

In this paper, COMSOL multiphysical field coupling program has been utilized to simulate $\mathrm{OH}$ cured samples under subzero temperature. The temperature development and heating regularity of the sample cured by $\mathrm{OH}$ curing under different environmental temperatures, different loading powers, and different sample sizes were mainly studied. The specific physical property parameters of materials used in the simulation process are shown in Table 1.

\section{Materials and Experimental Method}

3.1. Materials. The cementitious material used in this experiment is PO 42.5 cement. The chemical composition of the cement is shown in Table 2. The aggregate is fine quartz sand with the particle size range of $0.11-0.21 \mathrm{~mm}$, the fineness modulus of fine silica sand is 2.41 . CFs produced by Japan Toray have been chosen as the conductive filler; the diameter and the length of CFs are $7 \mu \mathrm{m}$ and $4 \mathrm{~mm}$, respectively. Detailed physical properties of CFs are shown in Table 3. CNFs have been utilized to construct microscopic conductive paths and the length and average diameter of CNFs are $20 \mathrm{~nm}$ and $100 \mathrm{~nm}$, respectively.
TABLE 1: The physical parameters for simulated materials.

\begin{tabular}{lc}
\hline Physical parameter & Value \\
\hline Thermal conductivity coefficient & $1.28 \mathrm{~W} \cdot \mathrm{m}^{-1} \cdot \mathrm{K}^{-1}$ \\
Density & $2300 \mathrm{~kg} / \mathrm{m}^{2}$ \\
Constant voltage capacitance & $1.26 \mathrm{~kJ} \cdot \mathrm{kg}^{-1} \cdot \mathrm{K}^{-1}$ \\
Relative dielectric constant & 4.5 \\
Electric conductivity & $3.97 \mathrm{~S} / \mathrm{m}$ \\
Radiance & 0.94 \\
Thermal expansion coefficient & $10 e-61 /{ }^{\circ} \mathrm{C}$ \\
\hline
\end{tabular}

TABLE 2: Chemical composition of cement.

\begin{tabular}{lcccccc}
\hline Oxide species & $\mathrm{SiO}_{2}$ & $\mathrm{Al}_{2} \mathrm{O}_{3}$ & $\mathrm{Fe}_{2} \mathrm{O}_{3}$ & $\mathrm{MgO}$ & $\mathrm{CaO}$ & $\mathrm{SO}_{2}$ \\
\hline $\begin{array}{l}\text { The oxide containing } \\
\text { (wt.\%) }\end{array}$ & 20.86 & 5.47 & 3.94 & 1.73 & 62.23 & 2.66
\end{tabular}

3.2. Sample Preparation and $\mathrm{OH}$ Curing Procedures. In this experiment, the mix design of $\mathrm{CFs} / \mathrm{CNFs}-\mathrm{CS}$ is as follows: the ratio of water to cement is 0.3 , the ratio of sand to cement is $1: 1$, the CFs addition amount is $0.75 \mathrm{vol} \%$, and the volumetric addition of CNFs is $0.2 \mathrm{vol} \%$. The detailed fabrication process of the samples has been listed as follows: firstly, CNFs and fine silica sand were put into the stirring 
TABle 3: Physical properties of CFs.

\begin{tabular}{lcccc}
\hline Diameter $(\mu \mathrm{m})$ & Tensile strength $(\mathrm{MPa})$ & Volume resistivity & Density & Carbon content \\
\hline 7 & 3800 & $1.5 \times 10^{-3} \Omega \cdot \mathrm{cm}$ & $1.76 \mathrm{~g} / \mathrm{cm}^{3}$ & $>95 \%$ \\
\hline
\end{tabular}

pot, and the CNFs were dispersed by rapid stirring with an eggbeater. Secondly, cement and CFs were sequentially placed in the pot, and the mixture was slowly stirred for 1 min with the mortar mixer and then stirred at high speed for 2 min to fully disperse CFs. Thirdly, the mixed solution of polycarboxylate superplasticizer (SP) and water was slowly added into the stirring pot and stirred for another $3 \mathrm{~min}$ to obtain final products. Finally, the mixture was poured into the plastic molds with the size of $350 \mathrm{~mm} \times 450 \mathrm{~mm} \times 40 \mathrm{~mm}$ embedded with two copper electrodes. The samples were then surface-smoothed and covered with plastic films. Twoelectrode method was used to measure the resistance of CFs/ CNFs-CS, the diagram of resistance measurement is depicted in Figure 3, and the resistivity $\rho$ is computed using the formulation as follows:

$$
\rho=\frac{\mathrm{RS}}{L},
$$

in which $R$ is the measured resistance; $S$ represents the crosssectional area of the composite; and $L$ is the distance between copper electrodes.

At the same time, fifteen thermocouples were arranged to record the temperature development of $\mathrm{CFs} / \mathrm{CNF}$ - $\mathrm{CS}$ sample cured by $\mathrm{OH}$ curing under subzero temperature. The diagram of the arrangement of thermocouples is shown in Figure 4. Moreover, the newly prepared sample was placed in a refrigerator with the constant temperature of $-20^{\circ} \mathrm{C}$. To promise the stability of the power $P$, the voltage was adjusted according to the measured resistivity value every two hours complying with the following equation:

$$
P=\frac{S U^{2}}{L \rho},
$$

in which $\mathrm{P}$ is the electric power; $\mathrm{U}$ represents the voltage; $\rho$ represents the resistivity; and the cross-sectional area of the sample and the distance between the electrodes are denoted with $S$ and $L$, respectively.

3.3. Characterization and Test. IThe effects of different influencing factors on the temperature development and heating forms can be obtained by COMSOL program. The optimal loading electric power density of $\mathrm{OH}$ curing was determined and further utilized to prepare CFs/CNFs-CS sample under $-20^{\circ} \mathrm{C}$ to verify the accuracy of modeling results from the aspect of experiments. CFs/CNFs-CS samples with the size of $350 \mathrm{~mm} \times 450 \mathrm{~mm} \times 40 \mathrm{~mm}$ were cured by $\mathrm{OH}$ curing with the temperature of $-20^{\circ} \mathrm{C}$ for 1 day and 2 days to figure out the effect of $\mathrm{OH}$ curing on strength formation under subzero temperature. While CFs/CNFs-CS samples were also cured by room temperature (RT) curing (with the temperature of $20^{\circ} \mathrm{C}$, humidity more than $95 \%$ ) for 1 day and 2 days, after the curing procedure, the cuboid

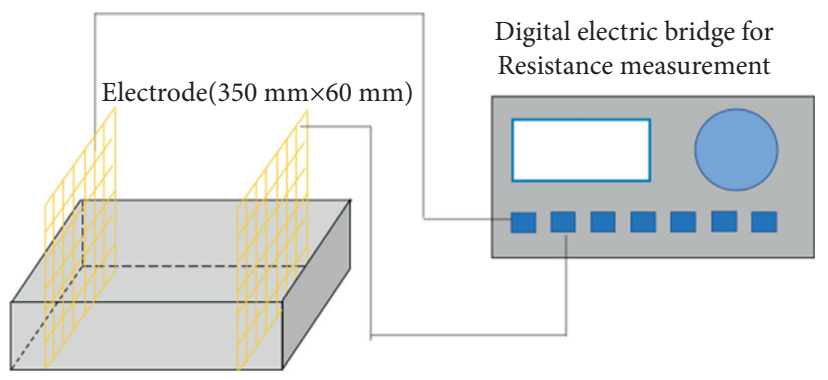

Figure 3: The diagram of resistance measurement.

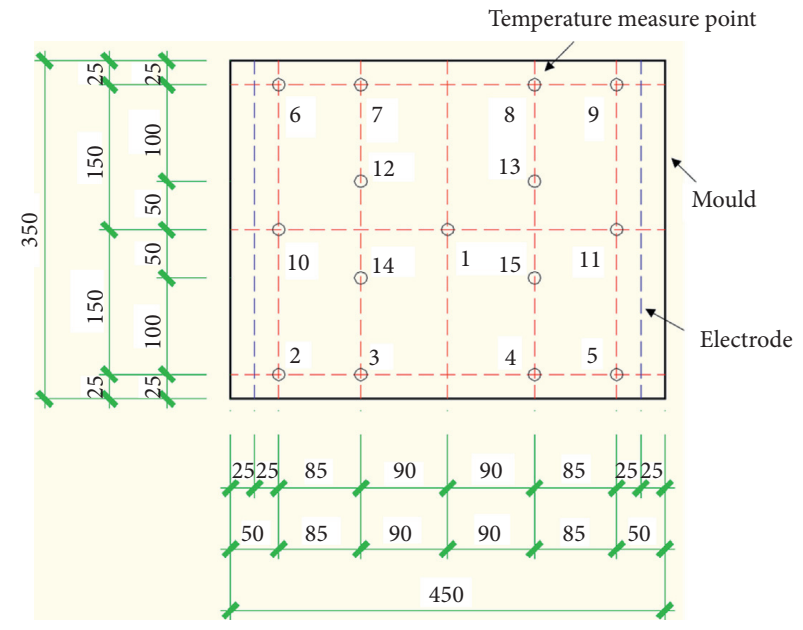

FIgURE 4: The diagram of the place of thermocouples.

sample with the size of $40 \mathrm{~mm} \times 40 \mathrm{~mm} \times 160 \mathrm{~mm}$ was cut from the middle of the slab. The compressive strength measurement of the samples $(40 \mathrm{~mm} \times 40 \mathrm{~mm} \times 160 \mathrm{~mm})$ was manufactured according to ISO679:1989 and GB/T 17671-1999 with the loading rate of $2400 \pm 200 \mathrm{~N} / \mathrm{s}$. The hydration process was terminated by immersing the small pieces of the samples into absolute ethanol. The small pieces were further cold dried for $6 \mathrm{~h}$ at $-60^{\circ} \mathrm{C}$. Scanning electron microscopes (SEM, Hitachi, 9 SU5000) were utilized to obtain the morphology information of the microstructure in CFs/CNFs-CS samples.

\section{Results and Discussion}

4.1. Numerical Analysis on the Effects of Different Influencing Factors on the Temperature Development and Distribution. In this section, numerical prediction model has been established by COMSOL program to simulate the temperature development and distribution of $\mathrm{OH}$ cured $\mathrm{CFs} / \mathrm{CNF}$ CS samples with different influencing factors. The effects of loading power density, environmental temperature, and structure geometric shape are taken into consideration. 
4.1.1. Loading Power Density. The temperature development of CFs/CNFs-CS samples is significantly affected by the loading electrical power density. The cuboid model with the geometric size of $350 \mathrm{~mm} \times 450 \mathrm{~mm} \times 40 \mathrm{~mm}$ was simulated, and the domain point probe was arranged at the center of the model with the coordinates of $(175,225,20)$. The temperature distribution of the model after $600 \mathrm{~min}$ has been analyzed under different loading power densities $\left(0 \mathrm{~W} / \mathrm{m}^{2}\right.$, $200 \mathrm{~W} / \mathrm{m}^{2}, 400 \mathrm{~W} / \mathrm{m}^{2}, 600 \mathrm{~W} / \mathrm{m}^{2}, 800 \mathrm{~W} / \mathrm{m}^{2}, 1000 \mathrm{~W} / \mathrm{m}^{2}$, $1200 \mathrm{~W} / \mathrm{m}^{2}$, and $1400 \mathrm{~W} / \mathrm{m}^{2}$ ). The results of simulation are shown in Figure 5 and the specific central temperatures of the samples are listed in Table 4. As shown in Figure 5, with the environmental temperature of $-20^{\circ} \mathrm{C}$, the temperature of the sample with the loading power density of $0 \mathrm{~W} / \mathrm{m}^{2}$ is always at subzero temperature, and this curing temperature cannot promise the hydration reaction of cementitious materials. However, with the loading power density of $200 \mathrm{~W} / \mathrm{m}^{2}, 400 \mathrm{~W} / \mathrm{m}^{2}, 600 \mathrm{~W} / \mathrm{m}^{2}$, and $800 \mathrm{~W} / \mathrm{m}^{2}$, the final curing temperatures at the center point of the sample reach around $10^{\circ} \mathrm{C}, 27^{\circ} \mathrm{C}, 45^{\circ} \mathrm{C}$, and $60^{\circ} \mathrm{C}$, respectively. It is worth mentioning that a proper curing temperature is essential to promise ongoing hydration process of cement-based materials [27, 28], leading to the sufficient strength formation, and at these temperatures, although the hydration reaction of concrete can be ensured, the promotion effect on its strength is not obvious. Moreover, with the loading power density of $1400 \mathrm{~W} / \mathrm{m}^{2}$, the peak temperature of the sample reaches up to $110^{\circ} \mathrm{C}$. This high curing temperature may lead to the decomposition of ettringite inside the sample, resulting in the degradation of mechanical properties for the sample $[29,30]$. Finally, with the loading power density of $1000 \mathrm{~W} / \mathrm{m}^{2}$ and $1200 \mathrm{~W} / \mathrm{m}^{2}$, the final curing temperature at the center of the sample can reach up to $80^{\circ} \mathrm{C}$ and $90^{\circ} \mathrm{C}$, respectively. With these curing temperatures, the strength of the samples can be formed rapidly and the mechanical properties of the samples will not be affected [31, 32]. In conclusion, the optimal loading power density range of $\mathrm{OH}$ cured slabs at $-20^{\circ} \mathrm{C}$ has been determined to be $1000 \mathrm{~W} /$ $\mathrm{m}^{2} \sim 1200 \mathrm{~W} / \mathrm{m}^{2}$.

4.1.2. Environmental Temperature. The environmental temperature also has a great influence on the samples cured by $\mathrm{OH}$ curing under ultra-low temperature. The temperature in northern China can reach up to $-40^{\circ} \mathrm{C}$ in winter. Therefore, it is necessary to simulate the temperature development of samples cured with different environmental temperatures. In this section, the loading power density has been determined to be $1000 \mathrm{~W} / \mathrm{m}^{2}$ to analyze the temperature distribution of the model with different environmental temperatures $\left(0^{\circ} \mathrm{C},-10^{\circ} \mathrm{C},-20^{\circ} \mathrm{C},-30^{\circ} \mathrm{C}\right.$, and $\left.-40^{\circ} \mathrm{C}\right)$, and the results are shown in Figure 6. It can be seen from Figure 6 that with the loading power density of $1000 \mathrm{~W} / \mathrm{m}^{2}$, the curing temperature of the sample can be maintained at $70^{\circ} \mathrm{C} \sim 80^{\circ} \mathrm{C}$ with the environmental temperature range of $-20^{\circ} \mathrm{C} \sim-40^{\circ} \mathrm{C}$ at the age of $600 \mathrm{~min}$. However, when the environmental temperature is between $-10^{\circ} \mathrm{C}$ and $0^{\circ} \mathrm{C}$, the peak temperatures of samples can reach up to $85^{\circ} \mathrm{C} \sim 90^{\circ} \mathrm{C}$. The hydration reaction of cementitious materials can be

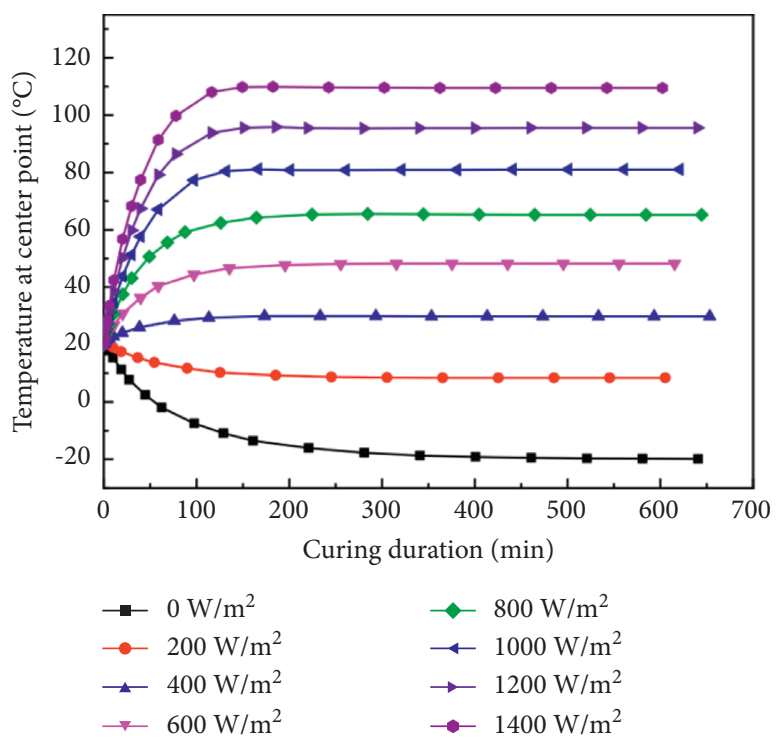

FIgURE 5: The simulated temperature at center point of the samples with different loading power densities.

TABLE 4: Simulated central temperatures of the samples with different loading power densities at $600 \mathrm{~min}$.

\begin{tabular}{lcccccccc}
\hline $\begin{array}{l}\text { Power density }(\mathrm{W} / \\
\left.\mathrm{m}^{2}\right)\end{array}$ & 0 & 200 & 400 & 600 & 800 & 1000 & 1200 & 1400 \\
\hline $\begin{array}{l}\text { Central } \\
\text { temperature }\left({ }^{\circ} \mathrm{C}\right)\end{array}$ & -20 & 10 & 27 & 43 & 61 & 80 & 91 & 108 \\
\hline
\end{tabular}

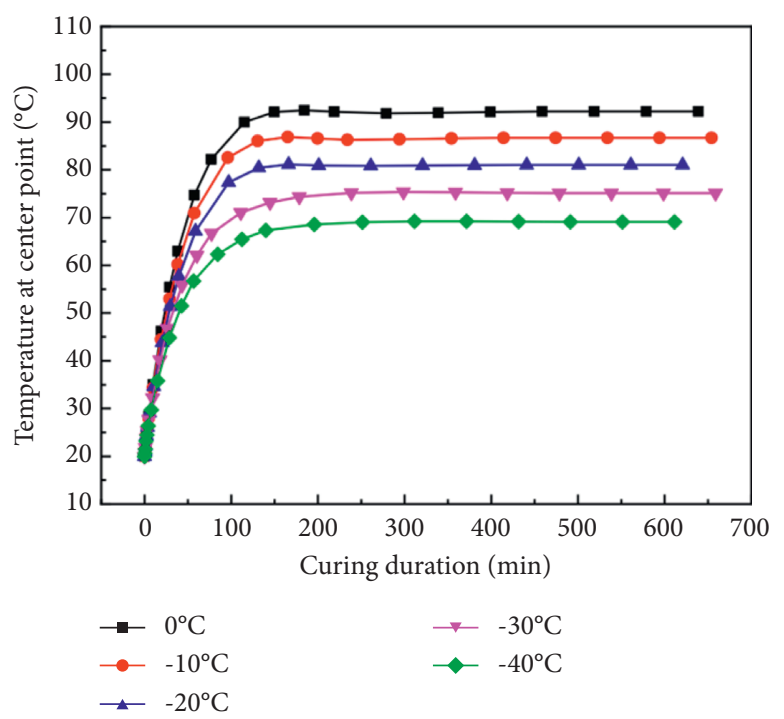

Figure 6: The simulated temperature at the center point of the sample with different environmental temperatures.

accelerated by properly increasing the curing temperature; this simulation result proves that $\mathrm{OH}$ curing can be utilized for concrete construction at severe cold regions in winter with the help of COMSOL numerical analysis. 
4.1.3. Structure Geometric Shape. After the modeling and prediction of the cuboid model, it can be concluded that $\mathrm{OH}$ curing can be guaranteed by adjusting the loading power density to reach the proper curing temperature of the sample under subzero temperature. In this section, in order to enhance the application of COMSOL program, the temperature field distributions of both cuboid model and cylinder model with the environmental temperature of $-20^{\circ} \mathrm{C}$ and the loading power density of $1000 \mathrm{~W} / \mathrm{m}^{2}$ were simulated, respectively. The size of the cuboid model is $350 \mathrm{~mm} \times 450 \mathrm{~mm} \times 40 \mathrm{~mm}$, and the size of the cylinder model is $\Phi 200 \mathrm{~mm} \times 1200 \mathrm{~mm}$. The simulation results are shown in Figures 7 and 8. It can be seen from Figure 7 that with the loading power density of $1000 \mathrm{~W} / \mathrm{m}^{2}$, the center temperature of the cuboid model is fairly high, while the temperature decreases gradually from the center point and the temperatures at four corners of the model exhibit lowest values. This phenomenon is due to that the four corners have the largest contact surface with the outside, thus the temperature at the corner decreases quicker. The cylinder model shows the same temperature distribution regularity, the temperature at the center of the sample is high, and the temperature far away from the central area gradually decreases. Moreover, with the increase of temperature, the temperature difference between the central region and the edge area becomes larger. When the curing time exceeds $200 \mathrm{~min}$, the temperature gradually tends to be stable, and the temperature is uniformly distributed in most areas of the whole cylinder. It can be concluded that COMSOL numerical analysis can be utilized to simulate the temperature development of the samples cured by $\mathrm{OH}$ curing under subzero temperature with different volumetric shapes.

\subsection{OH Curing of Nonmass CFs/CNFs-CS Sample Slab under} Ultra-Low Temperature. In the above discussion, the influence of different factors on the temperature distribution of $\mathrm{OH}$ cured $\mathrm{CFs} / \mathrm{CNFs}-\mathrm{CS}$ samples has been analyzed by COMSOL program. In order to further confirm the accuracy of simulation analysis, experiments were carried out to investigate the temperature development of CFs/CNFs-CS. The curing temperature of the samples can reach up to $80 \sim 90^{\circ} \mathrm{C}$ with the loading power density of $1000 \mathrm{~W} /$ $\mathrm{m}^{2} \sim 1200 \mathrm{~W} / \mathrm{m}^{2}$, which has been proved in the previous section. In this section, the loading power density has been determined to be $1100 \mathrm{~W} / \mathrm{m}^{2}$ to promise the proper curing temperature; based on this, the applied electrical power has been set to be $30 \mathrm{~W}$. Moreover, the arrangement of the thermocouples in the experiment is shown in Figure 4.

The distributions of temperature field have been recorded numerically and experimentally, and the results are respectively shown in Figures 9 and 10. Figure 9 exhibits the temperature distribution at the measured points of $\mathrm{OH}$ cured $\mathrm{CFs} / \mathrm{CNFs}-\mathrm{CS}$ sample at $-20^{\circ} \mathrm{C}$ at the first $500 \mathrm{~min}$ curing duration. It can be seen that the temperature development regularity of each point is almost same with the applied electrical power of $30 \mathrm{~W}$, indicating the uniform distribution of conductive paths constructed by CFs/CNFs. To be more specific, the curing temperature of CFs/CNFs-CS

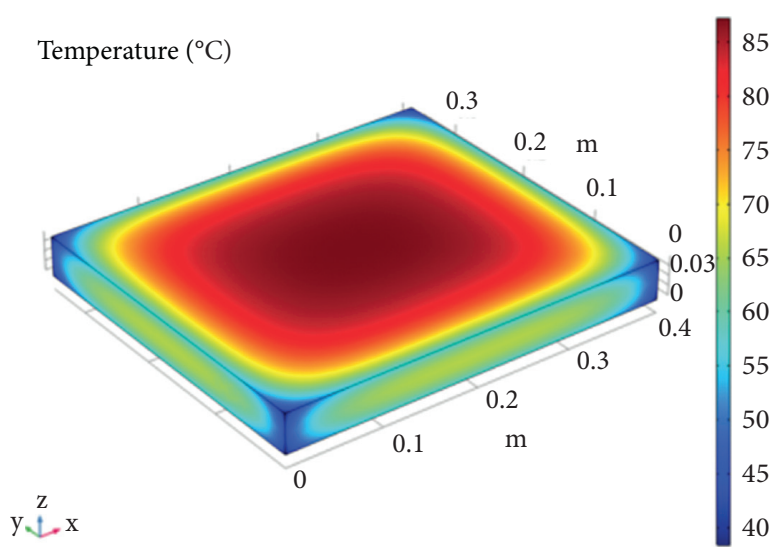

Figure 7: The surface temperature distribution of cuboid model with the loading electric power of $1000 \mathrm{~W} / \mathrm{m}^{2}$.

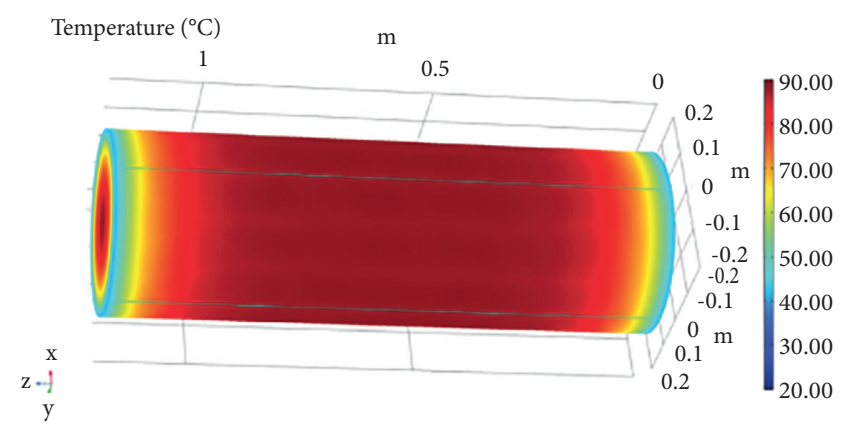

FIGURE 8: The surface temperature distribution of cylinder model with the loading electric power of $1100 \mathrm{~W} / \mathrm{m}^{2}$.

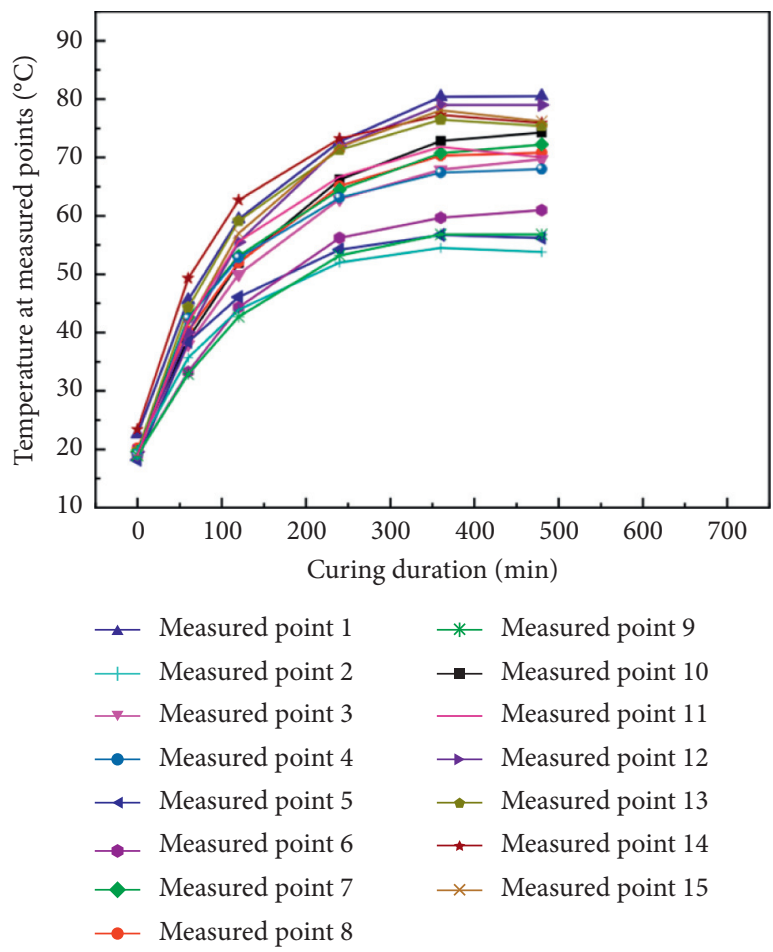

Figure 9: The actual temperature of CM-CF/CNFs slab. 


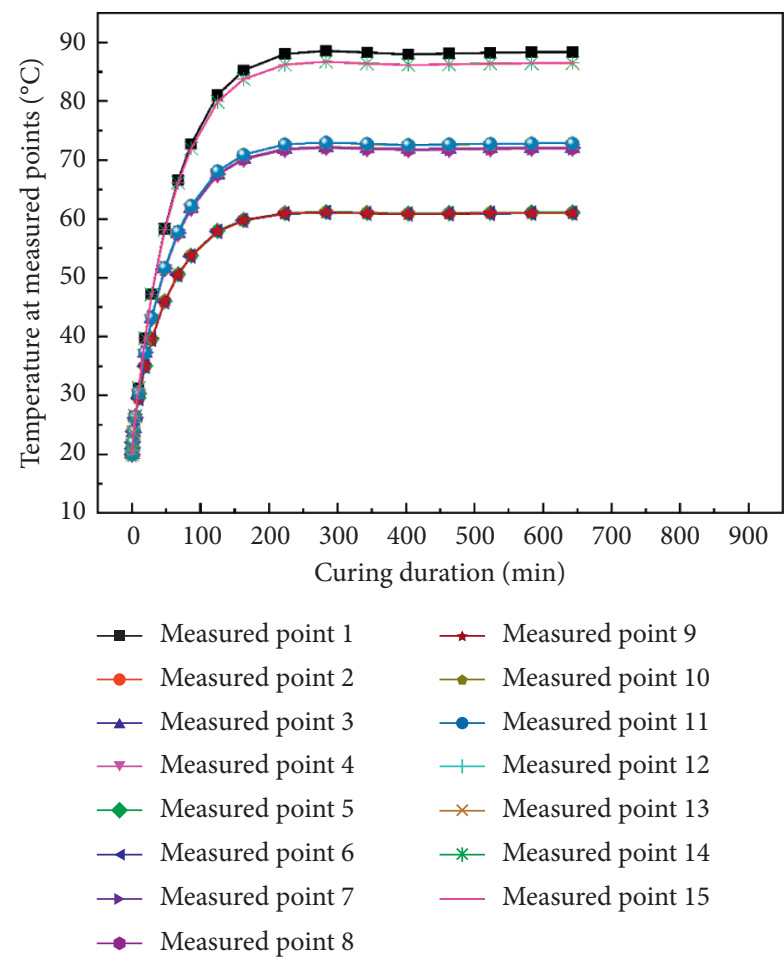

FIgURE 10: The simulated temperature of CM-CF/CNFs slab.

sample cured by $\mathrm{OH}$ curing increases obviously and reaches up to the peak temperature at $400 \mathrm{~min}$. However, the peak temperatures at different measured points seem to have little difference. The peak temperature at the center point of the sample is about $75-80^{\circ} \mathrm{C}$, while the peak temperature from the edge area exhibits lower value of $52-60^{\circ} \mathrm{C}$. In conclusion, the temperature at the center of the sample is generally higher than that around the sample. The reason for this difference is that the heat transfer path of the edge area is shorter than that of the central area. This causes that the heat dissipation speed is faster at the edge area of the sample compared with that at the central area of the sample $[33,34]$.

Figure 10 shows the temperature distribution of CFs/ CNFs-CS sample simulated by COMSOL program. The peak temperature at the central area of the sample is about $85-88^{\circ} \mathrm{C}$, while the peak temperature at the edge area is $60-70^{\circ} \mathrm{C}$ with the loading power density of $1100 \mathrm{~W} / \mathrm{m}^{2}$. Moreover, it takes 100 minutes with the heating rate of $0.68^{\circ} \mathrm{C} / \mathrm{min}$ for the peak temperature at the central area of the sample to raise from $20^{\circ} \mathrm{C}$ to $88^{\circ} \mathrm{C}$ by numerical simulation, while it takes 400 minutes with the heating rate of 0.15 ${ }^{\circ} \mathrm{C} / \mathrm{min}$ for the actual center temperature to rise from $20^{\circ} \mathrm{C}$ to $80^{\circ} \mathrm{C}$ by experimental measurement. It can be concluded that the temperature and heating rates simulated by COMSOL program are a little higher and faster than the measured temperature and heating rate during $\mathrm{OH}$ curing, and this is considered to be the reason that the actual curing condition of $\mathrm{OH}$ cured sample is much more complicated than the simulated environment. For example, the resistivity of the sample changed all the time during the curing process, leading to the actual applied power being always lower than the simulated power.
To further compare the curing temperatures of the samples, the peak temperature distribution of $\mathrm{CFs} / \mathrm{CNF}$ - $\mathrm{CS}$ sample measured numerically and experimentally is listed in Table 5. It can be seen from Table 5 that the whole temperature field simulated by COMSOL program is symmetrical distribution. The peak temperature at the center area is the highest, and the peak temperature gradually decreases with the increase of the distance from the center point. Moreover, it can be seen that the temperature prediction at the center of the sample is close to that of the actual $\mathrm{OH}$ cured sample, indicating the accuracy of the program. However, the peak temperature distribution of the sample cured by $\mathrm{OH}$ curing at $20^{\circ} \mathrm{C}$ is not as uniform as that obtained by the simulation analysis, but it still conforms to the temperature distribution regularity. This is considered to be that although CFs and CNFs could construct conductive paths inside the sample, the distribution of CFs/CNFs is not completely uniform, and there is still a certain gap of heating uniformity between the simulation analysis and actual experiment. However, the peak temperature of CFs/CNFs-CS sample cured by $\mathrm{OH}$ curing can reach up to $55-80^{\circ} \mathrm{C}$ at $-20^{\circ} \mathrm{C}$. This curing temperature is sufficient to promise the proper curing condition of the sample under ultra-low temperature by promoting the hydration reaction of cementitious materials to a great extent. Therefore, the developed simulation program is promising to guide the winter construction of nonmass cementitious materials cured by $\mathrm{OH}$ curing under ultra-low temperature.

4.3. Mechanical Properties. As shown in Figure 11, the compressive and flexural strengths of the samples cured with different curing conditions were measured. It can be seen from Figure 11(a) that the compressive strength of the samples cured by 1 day $\mathrm{OH}$ curing at $-20^{\circ} \mathrm{C}$ reaches up to $34.3 \mathrm{MPa}$, which is much greater than the critical frost resistance strength of $3.5 \mathrm{MPa}$. Moreover, it is also much higher than that of the sample cured by 1 day RT curing (19.7 MPa). Further, the compressive strength of 2 days $\mathrm{OH}$ cured $\mathrm{CFs} / \mathrm{CNFs}$-CS sample also increases obviously with the value of $48.2 \mathrm{MPa}$ compared with that of the sample cured by 2 days RT curing ( $38.1 \mathrm{MPa})$. This shows that the compressive strength of the sample can be significantly improved by $\mathrm{OH}$ curing with the electrical power of $30 \mathrm{~W}$ at $-20^{\circ} \mathrm{C}$.

Figure 11(b) represents the flexural strengths of CFs/ CNFs-CS samples cured with different conditions. The results indicate the flexural strengths of the samples developed in the same regularity as the compressive strengths. As shown in Figure 11(b), the flexural strength of 1 day $\mathrm{OH}$ cured sample is $10.5 \mathrm{MPa}$, which is much higher than that of the sample cured with 1 day RT curing (6.7 MPa). Moreover, the flexural strength of the sample subjected to 2 days $\mathrm{OH}$ curing reaches up to $11.5 \mathrm{MPa}$, which is $22.3 \%$ higher than that of the samples with 2 days RT curing.

4.4. SEM Analysis. SEM analysis of CFs/CNFs-CS samples subjected to different curing conditions was conducted and the results are shown in Figure 12. It can be seen from 
TABle 5: Peak temperatures of the samples measured numerically and experimentally.

\begin{tabular}{|c|c|c|c|c|c|c|c|c|}
\hline \multirow{4}{*}{ Simulated temperature $\left({ }^{\circ} \mathrm{C}\right)$ at different points } & 1 & 2 & 3 & 4 & 5 & 6 & 7 & 8 \\
\hline & 88.35 & 61.05 & 71.97 & 71.95 & 61.09 & 60.09 & 72.09 & 71.97 \\
\hline & 9 & 10 & 11 & 12 & 13 & 14 & 15 & \\
\hline & 61 & 72.82 & 72.82 & 86.49 & 86.49 & 86.5 & 86.48 & \\
\hline \multirow{4}{*}{ Measured temperature $\left({ }^{\circ} \mathrm{C}\right)$ at different points } & 1 & 2 & 3 & 4 & 5 & 6 & 7 & 8 \\
\hline & 80.5 & 56.2 & 63.5 & 68.1 & 57.6 & 54.1 & 69.7 & 70.9 \\
\hline & 9 & 10 & 11 & 12 & 13 & 14 & 15 & \\
\hline & 61.1 & 74.3 & 72.2 & 75.9 & 76.4 & 75.4 & 79 & \\
\hline
\end{tabular}

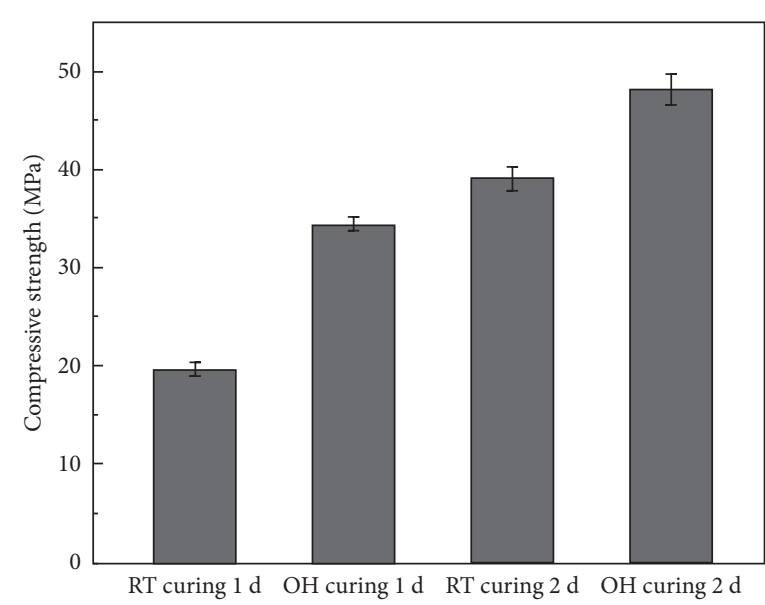

(a)

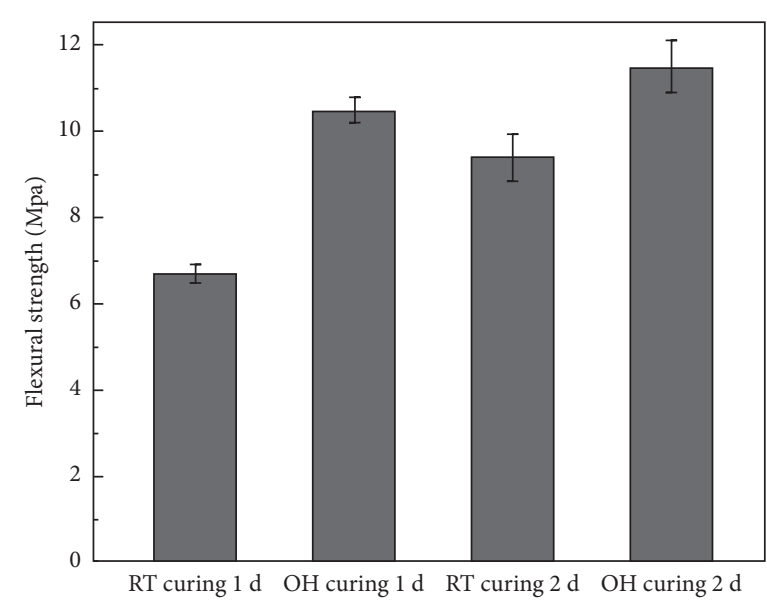

(b)

Figure 11: Mechanical properties of CF/CNF-CS samples. (a) Compressive strength and (b) flexural strength.
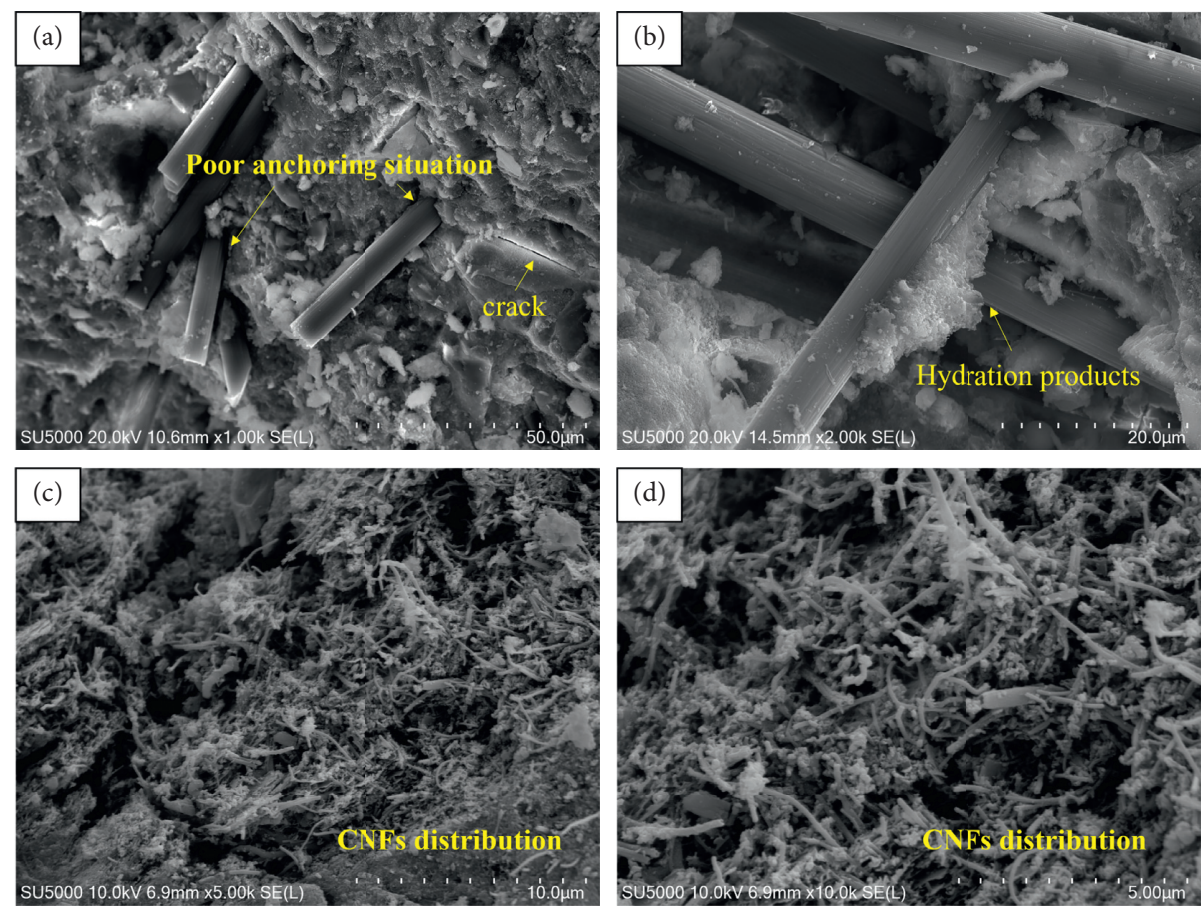

FIGURE 12: (a) SEM morphology of samples cured by 2 days RT curing with a magnification of 2000x, and the samples cured by 2 days OH curing with the magnifications of (b) 2000x, (c) 5000x, and (d) 10,000x. 
Figure 12(a) that the sample cured by 2 days RT curing exhibits relatively loose microstructure, and the surface of CFs are fairly smooth. However, the implementation of 2 days $\mathrm{OH}$ curing is beneficial for the microstructure of the samples. To be specific, a much denser microstructure can be found in 2 days $\mathrm{OH}$ cured samples, as shown in Figure 12(b). Moreover, hydration products inside the sample exhibit a trend to attach onto the surface of CFs, which can refine the ITZ between CFs and the matrix, and this is beneficial for mechanical properties of the samples. Figures $12(\mathrm{a})$ and 12 (b) respectively display the distribution situation of CFs and CNFs in the samples. A uniformly distributed situation of CNFs can be observed from Figures 12(a) and 12(b). This is beneficial to the stability of $\mathrm{OH}$ curing of the samples. In addition, the distribution situation of CNFs has been displayed in Figures 12(c) and 12(d); it is shown that CNFs can uniformly distribute in the sample to construct conductive network from the microscopic point of view. Based on the above microstructure evidences, it can be concluded that 2 days $\mathrm{OH}$ curing with $30 \mathrm{~W}$ electrical power is beneficial to the strength development of the CFs/CNFs-CS samples compared with 2 days RT curing.

\section{Conclusion}

This work numerically establishes the relationship between loading power and the curing temperature of the samples cured by $\mathrm{OH}$ curing, leading to the accurate guideline of applied power. This lays a solid foundation for concrete construction at cold region with high efficiency and low energy consumption. Detailed conclusions have been shown as follows:

(1) The numerical simulation results of COMSOL program show that the loading power and environmental temperature have a close influence on the curing temperature of nonmass CFs/CNFs-CS. Higher loading power and environmental temperature can lead to higher curing temperature. Moreover, the optimal loading power density of the sample calculated by COMSOL program is determined to be $1000 \mathrm{~W} / \mathrm{m}^{2} \sim 1200 \mathrm{~W} / \mathrm{m}^{2}$ at $-20^{\circ} \mathrm{C}$, and this loading power density can help the temperature at the central region of CFs/CNFs-CS sample reach up to $86-88^{\circ} \mathrm{C}$ in theory.

(2) The peak temperature of CFs/CNFs-CS sample reaches to $80.5^{\circ} \mathrm{C}$ at $-20^{\circ} \mathrm{C}$ with the loading electrical power of $30 \mathrm{~W}$ in the experimental measurement, which is very close to the numerical results. This proves the good prediction effect of COMSOL numerical program. Moreover, the simulated temperature field is symmetrical, and the temperature decreases from the center to the corner of the sample. The temperature field measured by the experiment basically conforms to this regularity.

(3) The compressive strengths of $\mathrm{OH}$ cured $\mathrm{CFs} / \mathrm{CNFs}$ CS samples for 1 day and 2 days are increased by $74.11 \%$ and $26.5 \%$, respectively, compared with those of the samples cured by 1 day and 2 days RT curing.
Moreover, the flexural strengths of the samples cured by $\mathrm{OH}$ curing for 1 day and 2 days reach up to $10.5 \mathrm{MPa}$ and $11.5 \mathrm{MPa}$, respectively. In addition, the results of SEM analysis show that the CFs/CNFs-CS samples cured by $\mathrm{OH}$ curing exhibit denser microstructure and better anchor situation between fibers and the matrix.

\section{Data Availability}

The raw data used to support the findings of this study are available from the corresponding author upon request.

\section{Conflicts of Interest}

The authors declare that they have no conflicts of interest.

\section{References}

[1] B. Ciuk, D. J. Haavik, and G. Haddad, "Standard specification for cold weather concreting (306.1-90)," Concrete, vol. 10, pp. 408-409, 1990.

[2] R. L. Kozikowski, W. C. Mccall, and B. A. Suprenant, "Cold weather concreting strategies," Concrete International, vol. 36, no. 5, pp. 45-49, 2014.

[3] R. Demirboga, F. Karagöl, Ri Polat et al., "The effects of urea on strength gaining of fresh concrete under the cold weather conditions," Construction and Building Materials, vol. 64, pp. 114-120, 2014.

[4] Z. Liu, A. Sha, M. Xing, and Z. Li, "Low temperature property and salt releasing characteristics of antifreeze asphalt concrete under static and dynamic conditions," Cold Regions Science and Technology, vol. 114, pp. 9-14, 2015.

[5] B. Xu, Z. Yang, L. Zhao, D. Cao, H. Zhang, and X. Shi, "Study on the antifreeze performance of porous cement stabilized macadam," Construction and Building Materials, vol. 208, no. 8, pp. 13-22, 2019.

[6] M. Ziolkowski and M. Kovtun, "Confined-Direct Electric Curing of $\mathrm{NaOH}$-activated fly ash based brick mixtures under free drainage conditions: Part 2. Confined-DEC versus oven curing," Construction and Building Materials, vol. 176, pp. 452-461, 2018.

[7] M. Ziolkowski and M. Kovtun, "Confined-Direct Electric Curing of $\mathrm{NaOH}$-activated fly ash based brick mixtures under free drainage conditions: Part 1. Factorial experimental design," Construction and Building Materials, vol. 155, pp. 1050-1062, 2017.

[8] Y. Liu, W. Tian, M. Wang, B. Qi, and W. Wang, "Rapid strength formation of on-site carbon fiber reinforced highperformance concrete cured by ohmic heating," Construction and Building Materials, vol. 244, Article ID 118344, 2020.

[9] Y. Liu, M. Wang, and W. Wang, "Ohmic heating curing of electrically conductive carbon nanofiber/cement-based composites to avoid frost damage under severely low temperature," Composites Part A: Applied Science and Manufacturing, vol. 115, pp. 236-246, 2018.

[10] Y. Liu, M. Wang, W. Tian, B. Qi, Z. Lei, and W. Wang, "Ohmic heating curing of carbon fiber/carbon nanofiber synergistically strengthening cement-based composites as repair/reinforcement materials used in ultra-low temperature environment," Composites Part A: Applied Science and Manufacturing, vol. 125, Article ID 105570, 2019. 
[11] W. Lei, Z. Xiao, Y. Hua, and X. Lv, "Investigation and application of fractal theory in cement-based materials: a review," Fractal and Fractinal, vol. 5, no. 4, p. 247, 2021.

[12] Z. Mi, Y. Hu, Q. Li, and H. Zhu, "Elevated temperature inversion phenomenon in fracture properties of concrete and its application to maturity model," Engineering Fracture Mechanics, vol. 199, pp. 294-307, 2018.

[13] N. J. Jin, I. Seung, Y. S. Choi, and J. Yeon, "Prediction of earlyage compressive strength of epoxy resin concrete using the maturity method," Construction and Building Materials, vol. 152, pp. 990-998, 2017.

[14] W. Li, Z. Huang, G. Hu, W. D. Hui, and S. P. Shah, "Early-age shrinkage development of ultra-high-performance concrete under heat curing treatment," Construction and Building Materials, vol. 131, pp. 767-774, 2017.

[15] K. F. Tan and J. Z. Zhu, "Influences of steam and autoclave curing on the strength and chloride permeability of high strength concrete," Materials and Structures, vol. 50, no. 1, pp. 1-9, 2017.

[16] L. Wang, X. Lu, X. Li et al., "Influence of reactivity and dosage of $\mathrm{MgO}$ expansive agent on shrinkage and crack resistance of face slab concrete," Cement and Concrete Composites, vol. 125, In press, Article ID 104333, 2022.

[17] S. Zandi, P. Saxena, and N. E. Gorji, "Numerical simulation of heat distribution in RGO-contacted perovskite solar cells using COMSOL," Solar Energy, vol. 197, pp. 105-110, 2020.

[18] T. Li, X. Yu, O. B. Habibzadeh, G. Lei, and A. J. Puppala, "Heating performance of a novel externally-heated geothermal bridge de-icing system: field tests and numerical simulations," Sustainable Energy Technologies and Assessments, vol. 46, Article ID 101280, 2021.

[19] B. Larwa, S. Cesari, M. Bottarelli, D. Boldor, G. M. Aita et al., "Study on thermal performance of a PCM enhanced hydronic radiant floor heating system," Energy, vol. 225, Article ID 120245, 2021.

[20] L. B. Leinson and A. Pérez, "Vector current conservation and neutrino emission from singlet-paired baryons in neutron stars," Physics Letters, Section B: Nuclear, Elementary Particle and High-Energy Physics, vol. 638, no. 2-3, pp. 114-118, 2006.

[21] R. J. Singh and T. B. Gohil, "The numerical analysis on the variation of electric potential, electric current and Lorentz force with its influence on buoyancy-driven conjugate heat transfer and fluid flow using OpenFOAM," Fusion Engineering and Design, vol. 148, Article ID 111300, 2019.

[22] A. Raicu, M. Barhalescu, and F. Memet, "Heat transfer original studies-Theory and applications [J]," IOP Conference Series: Materials Science and Engineering, vol. 591, no. 1, 2019.

[23] M. Kim, A. Sergis, S. J. Kim, and Y. Hardalupas, "Assessing the accuracy of the heat flux measurement for the study of boiling phenomena," International Journal of Heat and Mass Transfer, vol. 148, Article ID 119019, 2020.

[24] J. C. Cuevas and F. J. V. García, "Radiative heat transfer," ACS Photonics, vol. 5, no. 10, pp. 3896-3915, 2018.

[25] H. S. Roh, "Heat transfer theory for thermal non-equilibrium, quasi-equilibrium, and equilibrium," International Journal of Heat and Mass Transfer, vol. 64, pp. 661-670, 2013.

[26] V. Rozov, V. Belyakov, V. Kukhtin, E. Lamzin, I. Mazul, and S. Sytchevsky, "Strategy for solving a coupled problem of the electromagnetic load analysis and design optimization for local conducting structures to support the ITER blanket development," Fusion Engineering and Design, vol. 89, no. 11, pp. 2691-2708, 2014.

[27] Z. Li, D. J. Corr, B. Han, and S. P. Shah, "Investigating the effect of carbon nanotube on early age hydration of cementitious composites with isothermal calorimetry and Fourier transform infrared spectroscopy," Cement and Concrete Composites, vol. 107, Article ID 103513, 2020.

[28] W. Lei, R. Luo, W. Zhang, and M. Jin, "Effects of fineness and content of phosphorus slag on cement hydration, permeability, pore structure and fractal dimension of concrete," Fractals, vol. 29, no. 2, Article ID 2140004, 2021.

[29] S. L. Yang, S. G. Millard, M. N. Soutsos, S. J. Barnett, and T. T. Le, "Influence of aggregate and curing regime on the mechanical properties of ultra-high performance fibre reinforced concrete (UHPFRC)," Construction and Building Materials, vol. 23, no. 6, pp. 2291-2298, 2009.

[30] C. Kahanji, F. Ali, A. Nadjai, and N. Alam, "Effect of curing temperature on the behaviour of UHPFRC at elevated temperatures," Construction and Building Materials, vol. 182, pp. 670-681, 2018.

[31] P. Hu, D. J. Lu, X. Y. Fan, X. Zhou, and Z. S. Chen, "Phase change performance of sodium acetate trihydrate with AlN nanoparticles and CMC," Solar Energy Materials and Solar Cells, vol. 95, no. 9, pp. 2645-2649, 2011.

[32] Z. Pavlík, A. Trník, T. Kulovaná et al., "DSC and TG analysis of a blended binder based on waste ceramic powder and portland cement," International Journal of Thermophysics, vol. 37, no. 3, pp. 1-14, 2016.

[33] M. I. Stewart, "Heat transfer theory," Surface Production Operations, Elsevier, Amsterdam, Nertherlands, pp. 39-97, 2014.

[34] G. T. Polley, "Heat transfer and fluid flow," Physics in Technology, vol. 7, no. 3, pp. 132-133, 1976. 